\title{
IMMUNOPATHOLOGICAL FINDINGS IN A CAT WITH AURICULAR CHONDRITIS
}

\author{
Tais Meziara WILsON ${ }^{1}$, Mizael MACHADO ${ }^{1}$, Davi Emanuel Ribeiro De SoUSA ${ }^{1}$, \\ Tainã BRAÚNA ${ }^{2}$, Rafael TORRES NETO ${ }^{3}$, Renée LAUFER-AMORIM ${ }^{4}$, \\ Matias Pablo Juan SZABÓ ${ }^{5}$ and Marcio Botelho DE CASTRO ${ }^{1^{*}}$ \\ ${ }^{1}$ Laboratory of Veterinary Pathology and ${ }^{2}$ Small Animal Veterinary Hospital, School of \\ Veterinary Medicine, University of Brasília, Federal District, 70330-050 Brasília, DF, \\ Brazil; ${ }^{3}$ VetMol Laboratory, Botucatu, São Paulo and ${ }^{4}$ School of Veterinary Medicine \\ and Animal Science, São Paulo State University, Botucatu, São Paulo, Brazil; \\ ${ }^{5}$ Ixodology Laboratory, Faculty of Veterinary Medicine, Federal University of \\ Uberlândia, MG, Brazil
}

(Received 7 November 2018; accepted 15 February 2019)

At clinical examination, a 5-year-old male domestic short-haired cat exhibited painful swelling and erythema of the pinnae of both ears. Microscopically, the lesions on both pinnae were composed of diffuse granulomatous chondritis with degeneration and necrosis of the pinnal cartilage. Numerous mast cells were also observed within and surrounding the inflammatory lesion. Immunohistochemistry showed a mixed inflammatory infiltrate characterised by the predominance of macrophages (CD68+, MAC 387+ and Lysozyme+), T lymphocytes $(\mathrm{CD} 3+)$, some B lymphocytes $(\mathrm{CD} 79 \alpha+)$ and neutrophils. Immunopathological characterisation of the lesion showed a granulomatous inflammation profile and suggests that the morphological changes and immunopathogenesis of auricular chondritis in cats presents a similarity with relapsing polychondritis in humans.

Key words: Feline, macrophage, immunohistochemistry, immunopathogenesis, chondritis

Auricular chondritis (AC) is a rare condition characterised by inflammation and destruction of the cartilaginous tissues of the pinnae in animals and humans. A few cases were already reported in cats (Delmage and Kelly, 2001; Gerber et al., 2002), dogs (Sula, 2012), horses (Bowers and Slocombe, 2009), cattle (Bleul et al., 2006; Adissu et al., 2014) and rodents (Kitagaki and Hirota, 2007). A similar condition known as relapsing polychondritis (RP) occurs in humans and cats, which also affects other hyaline cartilage-containing tissues such as joints, eyes, airways and the cardiovascular system (Gerber et al., 2002; Lahmer et al., 2010; Arnaud et al., 2014).

*Corresponding author; E-mail: mbcastro@unb.br; Phone: 0055 (61) 3107-2808 
The pathogenesis of AC is unknown; however, it is speculated to be similar to that of human RP, with antibody production and reaction against type II collagen, matrilin-1 (cartilage-specific protein), as well as proteoglycan-rich tissues (Arnaud et al., 2014; Cantarini et al., 2014). Although the mechanisms of the disease are not completely known, the immune profile of inflammatory cells in the damaged cartilaginous tissues in humans with RP (Ouchi et al., 2011; Arima et al., 2016), and cattle (Adissu et al., 2014) and mice with AC (Kitagaki and Hirota, 2007) predominantly involves CD3+ and CD4+ T lymphocytes, CD68+ or Mac-1+ macrophages and a few neutrophils. Herein, we describe the immunopathological findings of an $\mathrm{AC}$ case in a cat.

A 5-year-old male domestic short-haired cat was taken to the veterinary service of the Veterinary Teaching Hospital, University of Brasilia with a 3month history of painful swelling and erythema at the edges and central region of the pinnae of both ears (Fig. 1a). The physical examination of the animal revealed good general condition, and no other clinical, biochemical or haematological changes were detected. Furthermore, the animal tested negative by serology for feline coronavirus, feline immunodeficiency and feline leukaemia viruses.

Fine-needle aspiration biopsy of the lesions showed a granulomatous inflammatory reaction characterised by many multinucleated giant cells, histiocytes, neutrophils and some individual spindle cells or cells arranged in clumps. Surgical biopsy samples measuring $3.0 \times 1.0 \mathrm{~cm}$ from the apex and lateral border of helix of both pinnae were collected and fixed in $10 \%$ buffered formalin, embedded in paraffin wax, sectioned at $4 \mu \mathrm{m}$, and stained with haematoxylin and eosin (HE) and toluidine blue (TB). Biopsy sections were also stained with Gram, Ziehl-Neelsen and Grocott and no bacterial or fungal infectious agent was detected.

Immunohistochemistry (IHC) using primary antibodies directed against CD79a (monoclonal mouse anti-CD79a antibody, Biocare Medical), CD3 (polyclonal rabbit anti-CD3 antibody, Dako Corp.), Myeloid/Histiocyte antigen (polyclonal rabbit anti-MAC 387 antibody, Dako Corp.), CD68 (monoclonal mouse anti-CD68, Dako Corp.), and lysozyme (polyclonal rabbit anti-lysozyme antibody, Dako Corp.) was performed using the biotin-peroxidase-streptavidin method (LSAB+ system-HRP, Dako Corp.), with 3,3'-diaminobenzidine (DAB+, Dako Corp.) on biopsy sections (Table 1). Histological sections of lymph nodes from a cat with no clinical signs of disease were used as positive control.

The percentage of each type of inflammatory cell (mast cells, polymorphonuclear and mononuclear cells) and those immunolabelled by each of the antibodies surrounding the auricular cartilage was determined using toluidine-bluestained sections in 10 randomly selected high-power fields $(40 \times)$.

The main microscopic findings were multifocal areas of cartilage disruption, and the formation of regenerative cartilaginous nodules surrounded by severe inflammatory infiltrate comprising macrophages, neutrophils, lymphocytes, plasma cells and multinucleated giant cells close to damaged cartilage areas (Fig. 1b). 


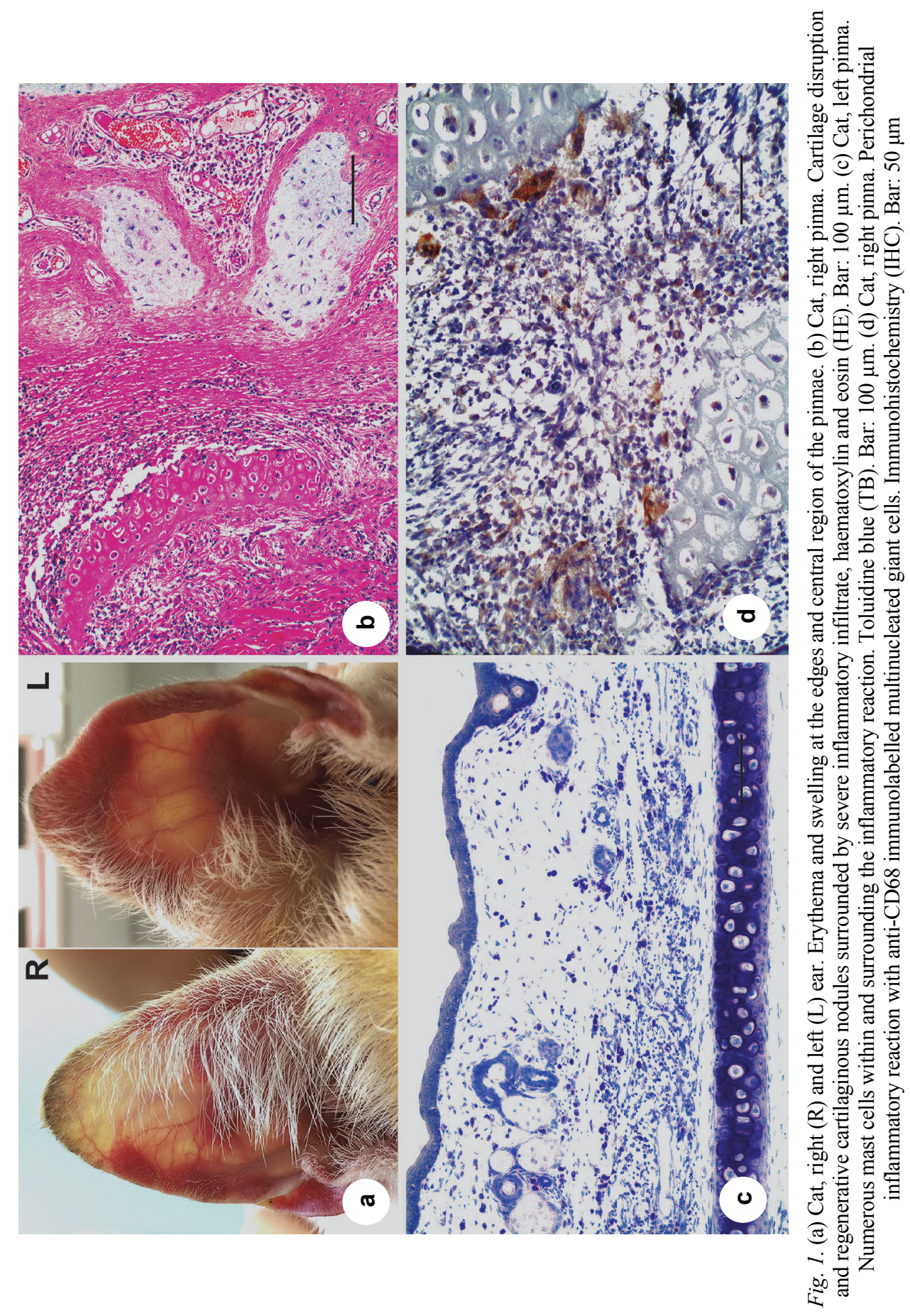


Mast cells were also observed in abundance within and surrounding the inflammatory reaction (Fig. 1c). The ear cartilage presented multifocal areas of cartilaginous matrix basophilia reduction, hypereosinophilia and pyknosis of some chondrocytes, surrounded by moderate to severe fibrosis and some lymphoplasmacytic perivascular cuffing.

The perichondrial inflammatory reaction was composed of $44 \%$ mononuclear cells, $25 \%$ polymorphonuclear cells, $22 \%$ mast cells and $9 \%$ degenerated and non-identified cells. Inflammatory cells showed immunolabelling by CD79a (10\%), CD3 (18\%), MAC 387 (13\%), lysozyme (83\%) and CD68 (19\%) with a strong reaction by multinucleated giant cells (Fig. 1d). Based on the clinical and pathological findings, a diagnosis of auricular chondritis was made.

Table 1

Antigen, origin of the primary antibodies and dilutions used in the immunostaining protocols applied to the samples tissues of the cat

\begin{tabular}{lcc}
\hline Antigen & Antibody clone*, & Dilution \\
\hline CD79 $\alpha$ & HM47/A9 & $1: 50$ \\
CD3 & Polyclonal rabbit & $1: 500$ \\
Myeloid/histiocyte & MAC 387 & $1: 200$ \\
CD68 & EBM11 & $1: 100$ \\
Lysozyme & Polyclonal rabbit & $1: 500$ \\
\hline
\end{tabular}

*Antigen retrieval: citrate $\mathrm{pH} 6.0,125^{\circ} \mathrm{C}, 3 \mathrm{~min}$, performed in a pressure cooker; ${ }^{\circledR}$ Detection method: biotin-peroxidase-streptavidin; ${ }^{\S} \mathrm{Chromogen}: \mathrm{DAB}=3,3^{\prime}$ diaminobenzidine

Immune-mediated inflammatory diseases are among the most challenging in terms of determining their pathogenesis and related injuries, as in the case of auricular chondritis (AC) in cats. Feline AC affects both ears with noninvolvement of other cartilaginous tissues and occurs predominantly in young and middle-aged short-haired cats (Delmage and Kelly, 2001; Gerber et al., 2002; Baba et al., 2009), as observed in the case reported here. Cats may also present involvement of the joints, respiratory, cardiovascular, ocular and other systems, in addition to the cartilage of the pinnae (Gerber et al., 2002; Baba et al., 2009), being similar to the relapsing polychondritis (RP) that affects middleaged humans (Lahmer et al., 2010; Arnaud et al., 2014; Cantarini et al., 2014).

Fine-needle aspiration biopsy of the lesions in the pinnae allowed the identification of the granulomatous inflammatory reaction. This technique, in addition to the case history and clinical findings, aids the presumptive diagnosis of AC in cats.

Histologically, auricular cartilage necrosis/degeneration and fibroplasia, surrounded by inflammatory infiltrate, are the hallmarks of the disease in feline species (Delmage and Kelly, 2001; Gerber et al., 2002; Baba et al., 2009). The regenerative nodules of cartilage observed here were previously reported in a heifer, in 
mice with experimentally induced AC (Kitagaki et al., 2003; Kitagaki and Hirota, 2007; Adissu et al., 2014), and in a cat with RP (Baba et al., 2009). The pinnal cartilage injury, in addition to releasing proinflammatory cytokines (Kitagaki and Hirota, 2007), possibly triggered the regenerative response of the chondrocytes.

The profile of inflammatory cells around the cartilage of the pinnae in the cat demonstrated a mixed-cell reaction composed predominantly of mononuclear cells with multinucleated giant cells. The perichondrial inflammatory infiltrate in cats with $\mathrm{AC}$ is generally composed of a variable number of mononuclear cells, neutrophils and a few multinuclear giant cells (Delmage and Kelly, 2001; Gerber et al., 2002; Baba et al., 2009). RP in mice and men is dominated by a histiocytic reaction and inflammatory infiltration by mononuclear cells in areas of cartilage damage (Kitagaki and Hirota, 2007; Ouchi et al., 2011), as observed in the case reported here. Based on the rarity of $\mathrm{AC}$, the limited pathological data available in domestic animals and unknown pathogenesis, the disease stage is suspected to be responsible for variations in the type of inflammatory cells (Baba et al., 2009).

Numerous mast cells within and surrounding the inflammatory lesion was a remarkable pathological feature observed in the pinnae of the cat. Numerous mast cells were also observed in the auricular dermis in a case of feline AC (Delmage and Kelly, 2001) and also in the auricular cartilage and upper dermis of mice with experimental RP (Kitagaki and Hirota, 2007).

The role of mast cells in the pathogenesis of $\mathrm{AC}$ in cats remains unknown. However, mast cells are involved in other cartilage inflammatory diseases such as rheumatoid arthritis, where they secrete cytokines and other inflammatory mediators (Nigrovic and Lee, 2005). In RP in humans, it is hypothesised that cartilage insult and the inflammatory process are due to genetic and triggering factors such as trauma, chemical, toxic and infectious agents, and are associated with the onset of autoimmunity pathogenesis (Bleul et al., 2006; Emmungil and Aydın, 2015; Lahmer et al., 2010). Therefore, it is possible to suspect that mast cells could potentiate or trigger the inflammatory process in feline AC, or even be associated with local allergy-associated responses.

Herein, the set of immunolabelled cells showed a mixed-inflammatory infiltrate characterised by the predominance of macrophages, $\mathrm{T}$ lymphocytes, some B lymphocytes and neutrophils. Our findings are similar to those reported in mice (Kitagaki and Hirota, 2007) and humans (Arima et al., 2016) with AC or RP. Most cells also presented immunolabelling by lysozyme, which can be attributed to their histiocytic and polymorphonuclear origins. Strong lysozyme positivity was previously detected in the auricular perichondrium of humans with RP (Arima et al., 2016; Ahn et al., 2017).

In cats and cattle with $\mathrm{AC}$ or RP, the inflammatory infiltrate in the perichondrium is predominantly lymphocytic (Gerber et al., 2002; Baba et al., 2009; Adissu et al., 2014), unlike the histiocytic and neutrophilic characteristics in the case reported here. CD4-positive T lymphocyte subsets associated with cytokine 
production such as IFN- $\gamma$, IL-2, and TNF- $\alpha$ are considered responsible for triggering the inflammatory process and cartilage injury (Ouchi et al., 2011; Arima et al., 2016). Therefore, the individual interpretation of the set of inflammatory cells in the few cases of $\mathrm{AC}$ in cats reported in the literature does not allow the establishment of a single pattern for the inflammatory response in the species.

Auricular chondritis is an unclear condition in cats. The similarity of the pathological findings observed here to those reported in humans and mice with $\mathrm{RP}$ and $\mathrm{AC}$ suggests that the immunopathogenesis of $\mathrm{AC}$ in cats is associated with an exacerbated immune response. This hypothesis, as well as the role of mast cells in the disease, still needs to be elucidated in order to understand the pathogenesis of the disease and to develop appropriate treatments for this condition in cats.

\section{References}

Adissu, H., Baird, J. D. and Wood, G. A. (2014): A case of bilateral auricular chondritis in a heifer. Case Reports Vet. Med. 2014, 1-4.

Ahn, S. W., Park, M. S., Jeong, H. B., Kwon, O. S., Yoon, B. N., Kin, H. S. and Choi, S. T. (2017): Relapsing polychondritis presented with encephalitis followed by brain atrophy. Exp. Neurobiol. 26, 66-69.

Arima, Y., Namiki, T., Ueno, M., Kato, K., Tokoro, S., Takayama, K., Miura, K. and Yokozeki, H. (2016): Histiocytoid Sweet syndrome: a novel association with relapsing polychondritis. Br. J. Dermatol. 174, 691-694.

Arnaud, L., Mathian, A., Haroche, J., Gorochov, G. and Amoura, Z. (2014): Pathogenesis of relapsing polychondritis: a 2013 update. Autoimmun. Rev. 13, 90-95.

Baba, T., Shimizu, A., Ohmuro, T., Uchida, N., Shibata, K., Nagata, M. and Shirota, K. (2009): Auricular chondritis associated with systemic joint and cartilage inflammation in a cat. J. Vet. Med. Sci. 71, 79-82.

Bleul, U., Ahrens, E., Stranzinger, G., Sydler, T., Ohlerth, S. and Braus, U. (2006): Auricular chondropathy in two Swiss Braunvieh heifers. Vet. Rec. 159, 890-892.

Bowers, J. R. and Slocombe, R. F. (2009): Auricular chondrosis in a horse. Aust. Vet. J. 87, 219-221.

Cantarini, L., Vitale, A., Brizi, M. G., Caso, F., Frediani, B., Punzi, L., Galeazzi, M. and Rigante, D. (2014): Diagnosis and classification of relapsing polychondritis. J. Autoimmun. 48, 53-59.

Delmage, D. A. and Kelly, D. F. (2001): Auricular chondritis in a cat. J. Small Anim. Pract. 42, 499-501.

Emmungil, H. and Aydın, S. Z. (2015): Relapsing polychondritis. Eur. Med. J. Rheumatol. 2, 155.

Gerber, B., Crottaz, M., von Tscharner, C. and Schärer, V. (2002): Feline relapsing polychondritis: two cases and a review of the literature. J. Feline Med. Surg. 4, 189-194.

Kitagaki, M. and Hirota, M. (2007): Auricular chondritis caused by metal ear tagging in C57BL/6 mice. Vet. Pathol. 44, 458-466.

Kitagaki, M., Suwa, T., Yanagi, M. and Shiratori, K. (2003): Auricular chondritis in young eartagged Crj: CD (SD) IGS rats. Lab. Anim. 37, 249-253.

Lahmer, T., Treiber, M., von Werder, A., Foerger, F., Knopf, A. Heemann, U. and Thuermel, K. (2010): Relapsing polychondritis: An autoimmune disease with many faces. Autoimmun. Rev. 9, 540-546.

Nigrovic, P. A. and Lee, D. M. (2005): Mast cells in inflammatory arthritis. Arthritis Res. Ther. 7, 1-11.

Ouchi, N., Uzuki, M., Kamataki, A., Miura, Y. and Sawai, T. (2011): Cartilage destruction is partly induced by the internal proteolytic enzymes and apoptotic phenomenon of chondrocytes in relapsing polychondritis. J. Rheumatol. 38, 730-737.

Sula, M. J. M. (2012): Tumors and tumorlike lesions of dog and cat ears. Vet. Clin. North Am. Small Anim. Pract. 42, 1161-1178. 